\title{
Breast carcinoma en cuirasse as a natural progression of untreated breast cancer
}

\author{
Lily Tung, Eric C. Stone, Meenakshi Bhasin, Sindu Sheth, Maria Nelson, Pulin A. Sheth, Debu Tripathy, Julie E. Lang*
}

Department of Surgery, University of Southern California, Los Angeles, United States

Received: August 14, 2015

Accepted: October 7, 2015

Online Published: November 3, 2015

DOI: $10.5430 /$ css.v2n1p46

URL: http://dx.doi.org/10.5430/css.v2n1p46

\begin{abstract}
Objective: Breast carcinoma en cuirasse is an aggressive manifestation of breast cancer, and is most often seen as a local recurrence. It is the most common primary malignancy to metastasize to the skin and palliative care is often the only option.

Methods: Retrospective review of the patient's chart was done.

Results: Our patient is a 65 year old female with no significant past medical or surgical history, who presented with a 2 year history of an enlarging left breast mass and left axillary mass, to the point where she had pain with breathing and restriction of chest wall expansion. Work-up of her breast and axillary masses showed carcinoma en cuirasse. Given the advanced stage of her disease, the patient was offered palliative care, which she declined.

Conclusions: Breast carcinoma en cuirasse is a rare manifestation of cutaneous metastases from breast cancer. While it is usually seen as a local recurrence, it can also be seen, as in our patient's case, as a natural progression of breast cancer that is difficult to treat. Our patient's case highlights the importance of early detection and treatment of breast cancer, as well as the surveillance for local recurrence.
\end{abstract}

Key Words: Breast carcinoma en cuirasse

\section{INTRODUCTION}

Breast cancer is not only the most common cancer among women, but it is also the most common cancer that can metastasize to the skin in women. Cutaneous metastases from internal malignancies account for $0.7 \%-9 \%$ of all metastases. ${ }^{[1-5]}$ Lookingbill et al. showed that breast cancer was the most common malignancy with breast cancer alone accounting for $51 \%$ of all cases of patients with cutaneous metastases from metastatic carcinoma, and $73 \%$ of all cases in women. ${ }^{[2]}$ Carcinoma en cuirasse, also known as scirrhous carcinoma, pachydermia, Acarcine eburnee ${ }^{[6]}$ is a type of cutaneous metastases with a distinctive clinical presentation. It typically starts with swelling, pitting edema, and scattered, firm papules and nodules overlying an erythematous breast.
These papules and nodules then coalesce into a thickened, leathery, plate-like mass that may be pruritic, painful, bleeding, or have foul-smelling discharge. ${ }^{[1,3,4,6]}$ Pathologically, it is seen across all receptor subtypes. Given the rarity of this disease, no pathological marker is known. While it is more commonly seen as a local recurrence, there have been reported cases of breast carcinoma en cuirasse as the initial presenting symptom. ${ }^{[4]}$ Here, we present a case of breast carcinoma en cuirasse as a natural progression from invasive HER2+ ductal carcinoma.

Clinical Practice Points:

- Breast cancer is the most common primary malignancy to metastasize to the skin.

\footnotetext{
*Correspondence: Julie E. Lang; Email: Julie.Lang@med.usc.edu; Address: Department of Surgery, University of Southern California, 1510 San Pablo Street, Suite 412, Los Angeles, CA 90033, United States.
} 
- Breast carcinoma en cuirasse is an aggressive manifestation of breast cancer, and is most often seen as a local recurrence, but can also be seen as the initial presentation.

- Breast carcinoma en cuirasse progresses from swelling, pitting edema, and papules and nodules overlying an erythematous breast, to a thick leathery plate-like mass that can be painful and bleed.

- Breast carcinoma en cuirasse is difficult to treat and palliative care is often the only option.

\section{Case reports}

Our patient is a 65-year-old Caucasian woman with no significant past medical or surgical history. She presented to our clinic with a 2-year history of enlarging left breast mass and left axillary mass, and pain throughout her left chest that increased with breathing and with restriction of chest expansion. She noted that she had ignored her condition as she believed it to be infectious in origin, and had failed a variety of antibiotic regimens as well as alternative therapies. On exam, the left breast was hard, fixed to her chest wall, and appeared to be entirely replaced by a fungating, plate-like mass. The overlying skin was lost with open weeping, bleeding surfaces and necrotic tissue (see Figure 1). Her PET/CT showed a bulky left primary breast tumor, regional axillary and supraclavicular adenopathy, contralateral axillary metastases, bilateral internal mammary metastases, diffuse bony metastases, and a left pleural effusion with evidence of direct extension and lymphangitic spread into her left thorax (see Figure 2). Punch biopsy showed a high-grade invasive ductal carcinoma that was estrogen receptor, progesterone receptor, and HER2-neu positive. Pathological analysis revealed a dense dermal proliferation of malignant epithelial cells arranged in a linear, trabecular, and sheet-like architecture. The cells were discohesive and displayed nuclear pleomorphism with prominent nucleoli and moderate vacuolated cytoplasm. No epidermal involvement was noted (see Figure 3 ). The patient was offered pain control and palliative systemic therapy but declined medical treatment.

\section{Discussion}

Cutaneous metastases from internal malignancies account for $0.7 \%-9 \%$ of all metastases. ${ }^{[1-5]}$ Breast cancer, however, is not only the most common cancer among women, but it is the most common malignancy with metastases to the skin in women. Lookingbill et al. showed that breast cancer accounted for $51 \%$ of all cases of patients with cutaneous metastases from metastatic carcinoma, and $73 \%$ of all cases in women, with the most common sites of cutaneous metastases being the chest and abdomen. ${ }^{[2,4]}$

Published by Sciedu Press

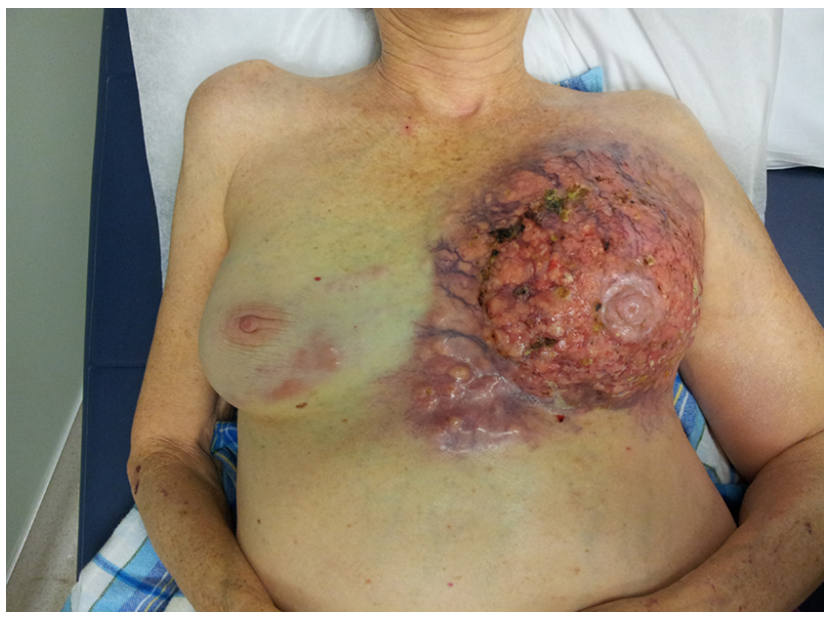

Figure 1. Breast carcinoma en cuirasse of left breast

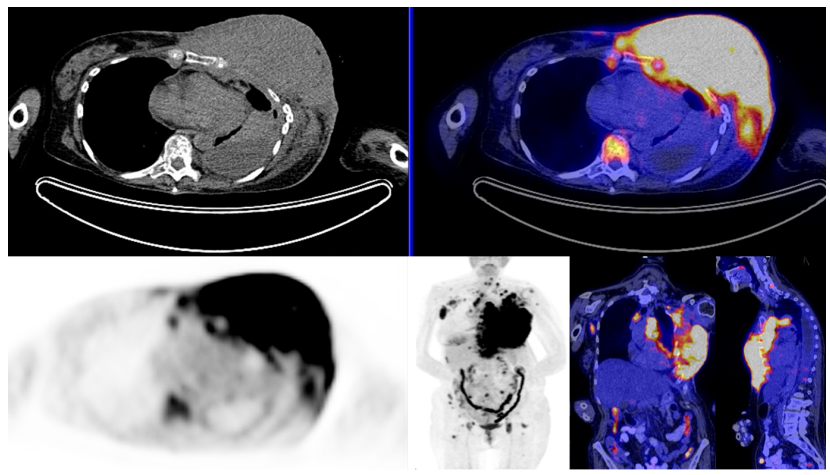

Figure 2. PET/CT of breast carcinoma en cuirasse of left breast

There are eight well-described clinicopathologic types of skin involvement from breast cancer: inflammatory breast carcinoma, telangiectatic metastatic breast carcinoma, nodular metastatic carcinoma, alopecia neoplastica, breast carcinoma of the inframammary crease, metastatic mammary carcinoma of the eyelid, Paget's disease, and carcinoma en cuirasse. ${ }^{[1,4]}$ First described by Velpeau in 1838, breast carcinoma en cuirasse was named for its resemblance to the breastplate armor worn by a cuirassier, or a cavalry solider. ${ }^{[4]}$ Since then, it has acquired other names, such as scirrhous carcinoma, pachydermia, and Acarcine eburnee. ${ }^{[6]}$ While breast carcinoma en cuirasse is usually seen as a local recurrence, it can also be seen as the initial presenting symptom. This disease typically starts with swelling, pitting edema, and firm papules and nodules on an erythematous base. These papules and nodules then coalesce into a thickened, leathery, plate-like mass of indurated plaques without associated inflammation that may be pruritic, painful, bleeding, or have foul-smelling discharge. ${ }^{[1,3,4,6]}$ In addition to the typical presentation, breast carcinoma en cuirasse has also been reported to present in unusual manners such as keloids of the chest $^{[6,7]}$ or with zosteriform metastasis. ${ }^{[8]}$ 

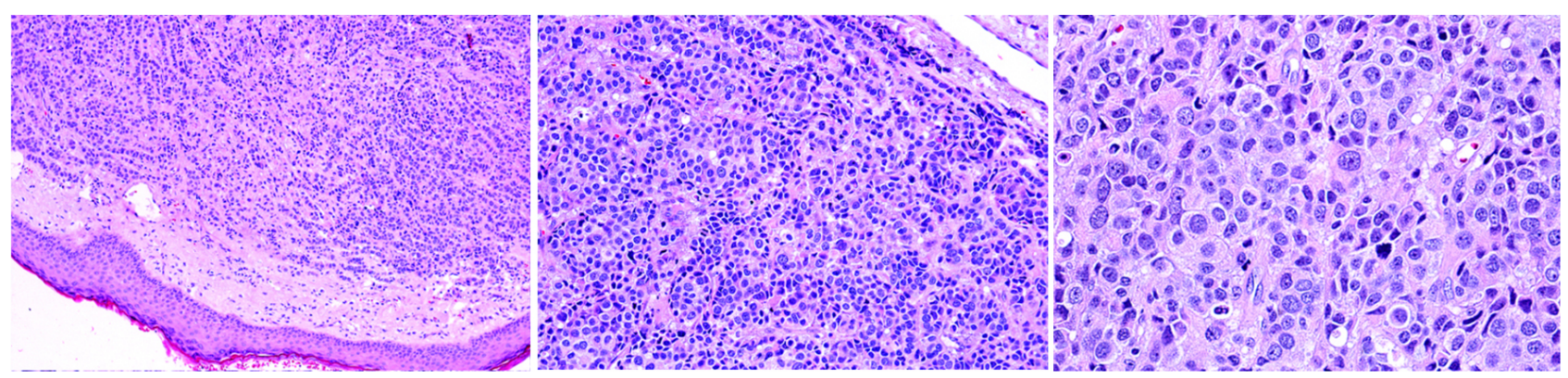

Figure 3. Photomicrograph of breast carcinoma en cuirasse of left breast punch biopsy $(10 \times, 20 \times, 40 \times)$

Histologically, the tissue in breast carcinoma en cuirasse is fibrotic, with tumor cells in between collagen bundles in a linear pattern. The densely fibrotic matrix, combined with the decreased vascularity seen in this disease, make them particularly resistant to chemotherapy. As such, prognosis is poor. In addition, given the rarity of the disease, there are no established pathological markers to help guide therapy. Treatment modalities that have been used include intra-lesional chemotherapy, radiotherapy, hormonal antagonists or HER2targeted therapies depending on receptor expression, and even snake venom. ${ }^{[6,8]}$ Unlike inflammatory breast cancer which begins in the breast ducts and then spreads to and remains contiguous with the skin, breast carcinoma en cuirasse is an actual metastasis of breast carcinoma to the skin. Given the lack of a definitive cure when in an advanced state, and difficulty of treatment for breast carcinoma en cuirasse, most patients are treated symptomatically or with palliative care, and usually succumb to local complications such as infection or to distant metastases.

\section{Conclusions}

Breast carcinoma en cuirasse is a rare manifestation of cutaneous metastases from breast cancer. While it is usually seen as a local recurrence, it can also be seen, as in our patient's case, as a natural progression of breast cancer. The difficulty of treating breast carcinoma en cuirasse highlights the importance of detecting and treating breast cancer early in the disease process, and the importance of surveillance for local recurrence.

\section{REFERENCES}

[1] Schwartz RA. Histopathologic aspects of cutaneous metastatic disease. J Am Acad Dermatol. 1995; 33: 649-57. http://dx.doi.o rg/10.1016/0190-9622(95) 91288-6

[2] Lookingbill DP, Spangler N, Helm KF. Cutaneous metastases in patients with metastatic carcinoma: a retrospective study of 4020 patients. J Am Acad Dermatol. 1993; 29: 228-36. http://dx. doi .org/10.1016/0190-9622(93)70173-Q

[3] Whitaker-Worth DI, Carlone V, Susser WS, et al. Dermatologic diseases of the breast and nipple. J Am Acad Dermatol. 2000; 43 733-51. PMid: 11050577. http://dx.doi.org/10.1067/mjd.2 000.109303

[4] Rolz-Cruz G, Kim CC. Tumor invasion of the skin. Dermatol Clin. 2008; 26: 89-102. PMid: 18023773. http://dx.doi.org/10.10
$16 / j . \operatorname{det} .2007 .08 .004$

[5] Oliveira GM, Zachetti DB, Barros HR, et al. Breast carcinoma en cuirasse - a case report. An Bras Dermatol. 2013; 88: 608-10. PMid: 24068134. http://dx.doi.org/10.1590/abd1806-484 1.20131926

[6] Mullinax K, Cohen JB. Carcinoma en cuirasse presenting as keloids of the chest. Dermatol Surg. 2004; 30: 226-8. PMid: 14756657.

[7] Vano-Galvan S, Moreno-Martin P, Salguero I, et al. Cutaneous metastases of breast carcinoma: a case report. Cases J. 2009; 2: 71. PMid: 19159440. http://dx.doi.org/10.1186/1757-1626-2-71

[8] Lakshmi C, Pillai SB, Sharma C, et al. Carcinoma en cuirasse of the breast with zosteriform metastasis. Indian J Dermatol Venereol Leprol. 2010; 76: 215. PMid: 20228567. http://dx.doi.org/10. 4103/0378-6323.60544 